\title{
Problems and Countermeasures of Express Delivery to Countryside in Quzhou of Zhejiang Province
}

\author{
Xiaoyun Zheng, Weiqing Mao ${ }^{1}$ \\ ${ }^{1}$ College of Economy and Trade Management, Quzhou University, Zhejiang, Quzhou 324000, \\ China
}

Keywords: Zhejiang Quzhou, E-commerce, Express deliver to countryside

\begin{abstract}
In recent years, the e-commerce in Quzhou is developed rapidly and tries to explore new business channels in towns by tap rural online shopping potentials, meanwhile, fresh food e-commerce targeting at rural special products and searching the shortcut of going out. But limited by small market and costs, the countryside express still exists "last kilometer" problem. This paper discussed and analyzed the problems exists in express market, combining with its future developing trends, try to find out a suitable solutions.
\end{abstract}

\section{Introduction}

Quzhou located in the west of Zhejiang province, neighbor to Jinhua and Lishui, an area of 8848.60 square kilometers with 255 million resident populations. In 2014, the total business volume of 47 express enterprises is 30.511 million, an increase of $96.9 \%$ with the total income of 279.546 million RMB, an increase of 94.9\%. From 2011 to 2014, the average annual growth rate of Quzhou express business volume is $78.3 \%$ and the average annual income growth rate is $57.1 \%$, higher than the average level of Zhejiang province.

With the impact of national strategy "internet+" and the exploitation of rural market, the scale of e-commerce in China is keep growth and ranking in the front row in the world. Although it is rapidly developed, most of them are concentrated in cities, and hard to realize delivery in countryside. Express, broadband and payment have become the major factors in restricting rural online shopping.

In order to solve the existing problems, Quzhou has made its own attempts, such as setting Hangbu Yunda direct agents, "home of express” on Shangfang, rural logistics companies delegated by Huitong and others whose express services are concentrated in key towns and unreachable to remote towns. At the same time, there are arbitrary charges and parcel security problems.

\section{Problems in Quzhou express industry}

Although the express industry of Quzhou is developed rapidly, its mechanism and institutional obstacles restrict need to be break through. The express industry is low concentrated with an obvious feature of price competition and requirements of improving its services, the ensure mechanism of universal postal service and network construction need to be improved, enterprises' low competitive power, lacking of professional workers, insufficient equipment and the quality of service need to be improved. The supervision and regulation capacity of government should be strengthened and the market order need be further standardized.

\section{Policy environment should be optimized}


The development of Quzhou express industry is in the bottleneck period and facing many difficulties like land constraints, financial and transportation difficulties. Express enterprises do not have independent operate fields which is bad for its long-term and stable development. Lacking of express infrastructures in city and community planning, and the phenomenon of express vehicle "hard to entry city, hard to dock, hard to handling” is outstanding. Quzhou municipal government has issued policies to support e-commerce, but lacking of tailored package of measures.

\section{Single means of market competition}

Quzhou express industry started in early nineties, as the amount of recipient is much larger than sending pieces, resulting a low level of profitability. The ratio of management workers is less than $10 \%$. The express industry is still in the extensive stage and the low price and homogenization competition is serious. The capacity of apply modern technology is weak and industrial services are not standardized. The level and quality of service need to be promoted.

\section{Insufficient of terminal delivery}

The terminal deliver capacity in the express industry is relatively insufficient, and the issue of "final 100 meters" and "last kilometer" is outstanding. Express enterprises and deliver outlets are mainly concentrated in urban areas and existing many blind spots in villages and mountainous. The network in rural areas should be further extended and the gap between them needs to be reduced.

\section{Application level of science and technology is not high}

The scale of express companies in Quzhou is universally small, and the information level is not high. Most companies' investments in delivery vehicles and sorting equipment is insufficient, lacking of automated sorting equipment as the ratio of equipped sorting belt is only $35.5 \%$, resulting low sorting efficiency and poor labor productivity.

\section{Low quality of employees}

Express employees are lacking of systematic and regular professional training. In 2014, the postal workers within the city is 2411 , in which only $9 \%$ is college or higher educated, junior college workers accounted for $20 \%$, high school is $35 \%$ and primary and below is $36 \%$.

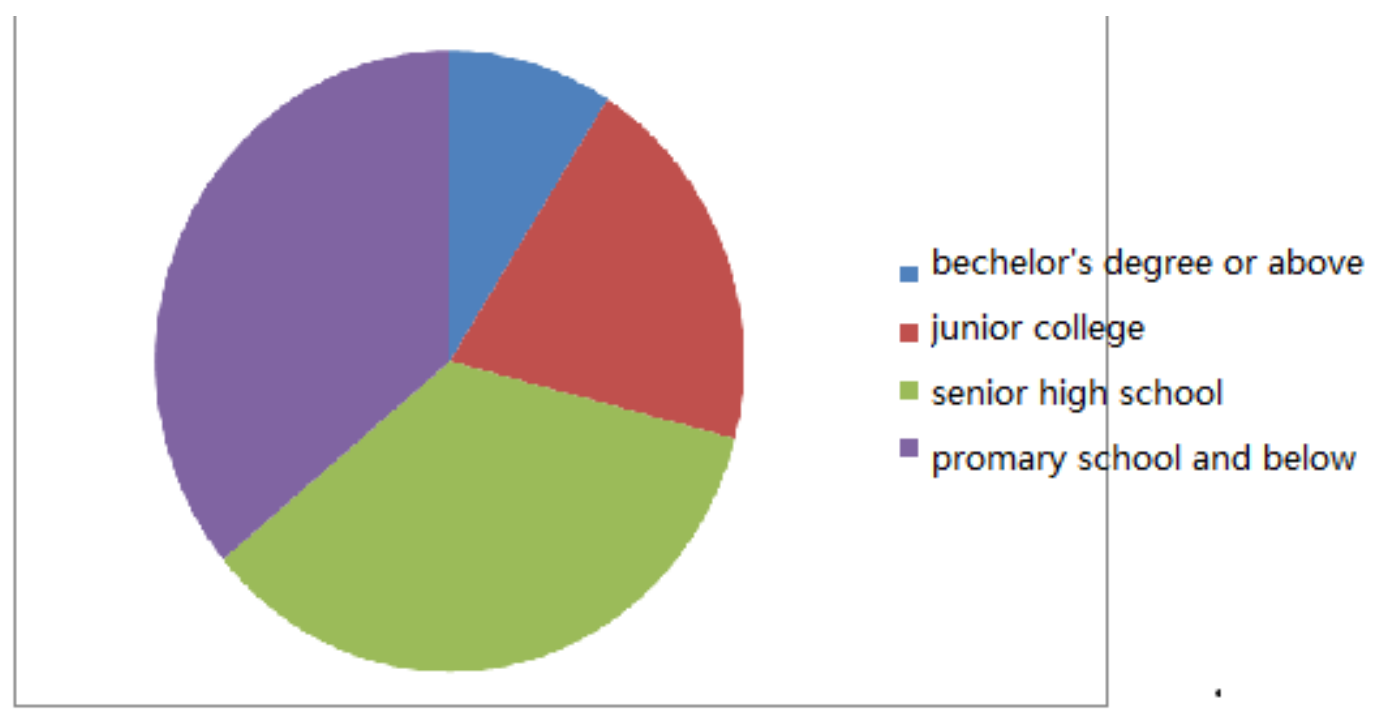

Fig 1 Education distributions of Quzhou express workers

\section{New situations during “ $13^{\text {th }}$ Five-Year Plan” period}

With the implementation of the "speed up the transformation and upgrading of traditional industries, promoting the development of service industry, especially modern service industry" and "internet+" 
strategies, China has entered the era of "public entrepreneurship and innovation”. In this period, Quzhou has issued a series of policies to providing impetus for its postal delivery industry.

Regional economic steadily developed, promote the sustained growth of express demand Quzhou is located in the Yangtze River and Haixi economic zones, with unique geographical advantages, it is an important logistics node city. With the perfect of modern transportation network, the economic in Quzhou continues to developing steadily, providing new opportunity for express industry. In 2014, the per express amount in the city is 11.97, below the average level of 44.62 in Zhejiang province, the incoming and outgoing ratio is also lower than the provincial average, which means the express industry has an enormous room for development.

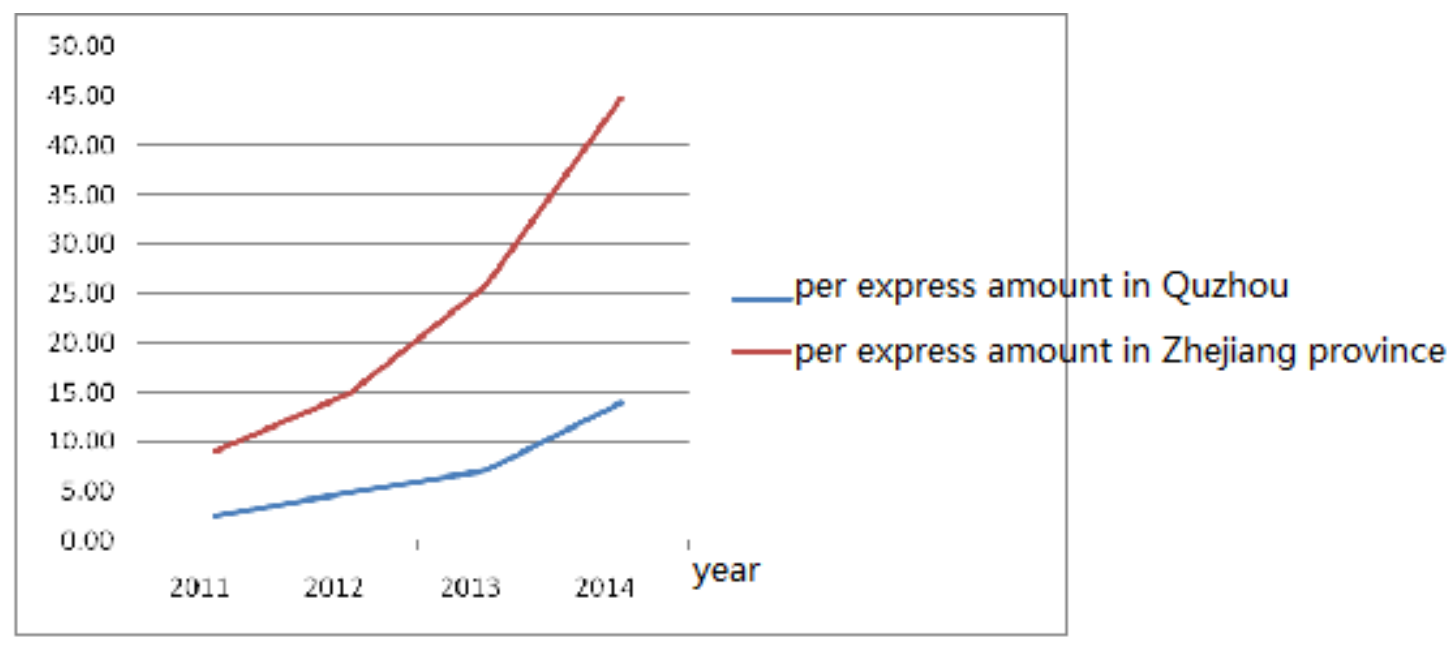

Fig 2 capita express amount in Quzhou

With the rapid growth of e-commerce, postal express industry is facing new opportunities

In 2014, Quzhou achieved the total e-commerce transaction of 30 billion RMB, an increase of $100 \%$. Within the municipal districts, there are fifteen standardized cross-border e-commerce zones. E-commerce has become an important force in pushing restructuring and development of economic, which will promoting the development of postal express industry.

With the advancing of science and technology, service capabilities of postal express continues to increase

With the popularization of information and internet of things technology and the construction of automated sorting transport, information collection, the handling capacity of express is improved. The widely application of GPS, GIS and other IT equipment greatly improved the intelligence service ability. The construction of E-post cabinet and other intelligent terminal facilities greatly improved the delivery capacities and the production efficiency.

Increasingly competition within the industry, which need to be restructuring and upgrading With the emerging of new demands, formats and technologies, the competition between the traditional express markets becomes more intense. For the slowing down market demands and increasingly standardized regulations, a number of small-scale and low income marginal companies will be eliminated or merged, enhancing the industry concentration.

\section{Development countermeasures for Quzhou express industry}

Planning the spatial network layout of express industry 
Promoting the construction of express zones, achieve industry gathering, functional integration and intensive management, forming a rational spatial distribution of postal stations. Support the strategy of "express deliver to countryside". In remote mountainous and regions, guiding the express network docking with other transportation methods like universal postal network and rural passenger transport, and actively expand the service scope, adding all the towns into the service network of arriving within 24 hours in same towns.

\section{Promoting the depth integration of express and industry}

Encourage the interaction within express companies and between related industries, promoting the integration of industrial chain, supply chain and value chain, boosting the industrial restructuring and upgrading. Encourage express companies and manufacturing enterprises within the area to establish a long-term stable strategic partnership and to outsourced logistics express service. Construct a cooperation and development platform with large scale manufacturing companies and e-commerce, establishing a rapid distribution system.

\section{Promoting the restructuring and upgrading of express enterprises}

First, management innovation and guide enterprises to innovate developing paths, promote the implementation of commitment to service and differentiation competition, changing the emphasis on price competition to service competition and transition to a modern enterprises system.

Second, using electronic and distance education mode to improving the efficiency and quality of education and training. Encourage enterprises to enhance the cultural construction, making career development plans for employees, providing a good environment for career development and solving "recruitment difficulties" in mechanism aspect.

Third, promoting the application of "cloud computing” and "internet of things" and other related technologies and increase the utilization of sorting mechanization and RFID, improve operational efficiency and reduce labor intensity. Promote the use of information technology and equipment to increase services and production efficiency.

\section{Accelerate the "express deliver to countryside" project}

Encourage the express delivery companies keep pace with the development of rural e-commerce, establish service outlets in towns where have small business volumes, cooperate with countryside stores, integrated rural service, agricultural marketing agencies and others. Support postal express companies cooperate within industry. Promote the postal infrastructure to handle (agent) express service, building an integrated service platform, solving the "last kilometer" problem.

\section{Optimize spatial layout and construct express logistics zone}

Rational planning of municipal distribution center, county transit center, town outlets, community (rural) network and other infrastructures, support postal enterprises, famous e-commerce companies and facilitate business entering the village and setting mail and express distribution centers. Optimize the spatial distribution and integration of resources, promoting the healthy development of express delivery.

\section{Strengthen industrial supervision and regulation}

Based on "Postal law" and "universal postal service standards", strengthen supervision and inspection on universal service, carry out the express license system, regulate the behavior of market players and create a fair competitive market environment. Strengthen law enforcement and industry self-regulation, establishing a fair competition system. Accelerate the construction of quality evaluation standards, monitoring companies to fulfill the goods safety responsibility, and acting the services security commitments, effectively ensure the safety of delivery channels. 


\section{Conclusions}

With the popularity of online shopping, more and more rural residents began to accept it. Expand the delivery scope and solve the shortcomings of rural delivery need the co-operation of governments, postal regulators, the transport sector, postal companies, express enterprises and e-commerce and others.

Quzhou postal express industry need to continue to promote its standard operations, to achieving quantity and quality increasing based on the " $13^{\text {th }}$ five-year" plans, "by 2020 , business income (exclude the income of Postbank) breakthrough 1.6 billion, an annual increase of 25\%-30\%, in which the quantity of express business exceed 150 million, to achieve the income of 1.35 billion $\mathrm{RMB}$, an increase of more than $30 \%$, realizing "outlets in towns, express in village” and service satisfaction continues to improve.”

\section{Acknowledgement}

This article is the study results of general project "Study on the route of express delivery to the countryside in Quzhou” from Quzhou Federation of Social Sciences Department. Project number: 15 QSKG09LX.

\section{References}

[1] State Post Bureau of The People’s Republic of China. Postal universal service "12th five-year" plan, 2012. (In Chinese)

[2] National Postal Development Research Centre Development report of China's express delivery industry in 2014, 2014. (In Chinese)

[3] Zhejiang Provincial Post Office. Zhejiang province "12th Five-Year” plans of postal industry. 2011. (In Chinese)

[4] Hangzhou Post Office. Hangzhou express service industry development plan, 2013. (In Chinese)

[5] Tang C et al. Study on the interaction between agricultural logistics and modern agriculture. A project of Zhejiang Department of Transportation, 2007. (In Chinese)

[6] Ma D. Analysis on the status of rural tourism in Quzhou and its countermeasures. South China Agriculture, 2014 (09): 95-98. (In Chinese)

[7] Mao W. SWOT analysis and developing strategies of farm product in undeveloped areas---a case study of Quzhou. China Business Update, 2011 (2): 70-71. (In Chinese)

[8] Zha, W. Survey and reflections of rural online shopping. Electronic Commerce, 2015(1): 27-28. (In Chinese)

[9] Liu Y. Exploration of rural business development mode of private express. Modern Business Trade Industry, 2104, 26(21): 52-54. (In Chinese) 